\title{
RE-THEORISING CONSUMER LAW *
}

Keywords

Competing ethics-self-interest/reliance-need

\begin{abstract}
This article develops a new theoretical framework for understanding consumer contract law, one based on competing ethics of self-interest/reliance and need. It shows how this is a better way of understanding choices as to levels of protection than the traditional 'freedom versus fairness' framework. The self-interest/reliance ethic favours rules allowing traders to use processes to escape responsibility for poor quality and harsh outcomes, while the need ethic is concerned with consumer weaknesses and better protects against such outcomes. The article also shows that need based rules are usually more effective at improving clarity and certainty, and where such rules cause uncertainty, at least as much uncertainty is caused by the alternative self-interest/reliance based rules.
\end{abstract}

\section{INTRODUCTION}

This article considers how consumer contract law in the UK is influenced by alternative ethical visions of the ideal market order. There has been previous work, for example, on the relatively narrow question as to how competing judicial ethics affect interpretation of rules on standard terms and commercial practices-the rules being interpreted by some judges in ways that prioritise business self-interest and consumer self-reliance, and by other judges in ways that are more protective of consumers. ${ }^{1}$ This article is significantly more ambitious in scope. It focuses on a much larger part of consumer contract law: the legislative rules on conformity of goods, services and digital content (DC), and on unfair terms. It also asks a number of important new questions about the nature and significance of these ethics: What theoretical framework can explain these ethics? How does such a framework improve our understanding of different visions of consumer protection? How are these different visions reflected in the actual rules? These are the "ethics and protection" questions. Then there is the question as to how competing ethics affect legal clarity and certainty-the "ethics and clarity/certainty" question. The remainder of this Introduction explains how the answers to these questions are developed over the subsequent Parts of the article, and why these issues are so important.

The "ethics and protection" questions are dealt with over Parts II-IV. Part II proposes a new competing ethics framework and shows why this is a highly effective way of describing alternative visions of consumer protection. Under this framework, there is one ethical vision of consumer law which places strong emphasis on business self-interest/consumer selfreliance. This would be expressed in rules providing limited consumer protection: allowing businesses to use their "inputs" or "processes", to escape responsibility for poor quality outcomes, and to legitimise imposition of outcomes that are harsh on consumers. Towards

\footnotetext{
*Chris Willett, Professor of Commercial Law, University of Essex. School of Law, Wivenhoe Park, Colchester CO7 4SQ: Email: cwillett@essex.ac.uk. My thanks are due to Professors Roger Brownsword, Lorna Fox-O’Mahony, Onyeka Osuji, Sabine Michalowski, Christian Twigg-Flesner and the anonymous reviewers for comments on drafts.

${ }^{1}$ C. Willett, "General Clauses and the Competing Ethics of European Consumer Law in the UK" [2012] C.L.J. 412, developing M. Weber, The Theory of Social and Economic Organization, translated by T. Parsons (1947), 184-186 on how "substantive" rationality (which includes choices about rules) involves value judgments (cf. "formal" rationality denying such value judgments).
} 
the other end of the ethical spectrum, is an ethic more sensitive to consumer "need", i.e. the need for consumers to be protected due to their perceived weaker position. This would be expressed in rules that prioritise protecting consumers from poor quality and harsh "outcomes". Part II argues that this is a more effective way of explaining consumer protection choices, than the "freedom versus fairness" framework previously used to explain consumer contract law. The "self-interest/reliance versus need" framework is more nuanced and precise. It makes a clear distinction between regulatory choices, while the distinction between "freedom" and "fairness" based options is often more blurred.

Parts III and IV use important recent reforms to show how the competing ethics of selfinterest/reliance and need play out in the actual consumer contract law regime: demonstrating that the regime reflects a tension between these competing visions of consumer protection. Recent years have seen various important reforms to business to consumer (B2C) contract law, e.g. on insurance, information and cancellation rights, and remedies for unfair practices. ${ }^{2}$ However, the Consumer Rights Act (CRA) 2015 is by far the most wide ranging and significant reform, and serves as the case study here on the "ethics and protection" questions. Parts 1 and 2 alone ${ }^{3}$ consolidate and reform B2C contract law rules affecting hundreds of millions of daily B2C contracts ${ }^{4}$ : on conformity of goods, DC and services; remedies for non-conformity; and unfair contract terms. ${ }^{5}$ Consistently high levels of consumer detriment are caused by defective goods, DC and services, and unfair contract terms. ${ }^{6}$ So, it is particularly important to understand how the legal response to this has been shaped by competing ethics. There has already been work on how the CRA and the other recent reforms have moved the $\mathrm{B} 2 \mathrm{C}$ regime further from the values of business to business (B2B) contract law. ${ }^{7}$ However, this article digs more deeply, showing that the CRA actually contains rules reflecting a mixture of values: those reflecting the consumer need ethic, guaranteeing protection against poor quality and harsh outcomes; and those (less protective) rules reflecting the self-interest/reliance ethic, allowing businesses to use their 'inputs' or 'processes,' to escape responsibility for poor quality outcomes, and to legitimise harsh outcomes.

Parts III and IV also use the CRA to show how competing ethics affect clarity and certainty (the "ethics and clarity/certainty" question). It is shown that need-based rules are usually better at improving clarity and certainty, than rules based on the self-interest/reliance ethic; and that where need-based rules do cause some uncertainty, at least as much uncertainty is caused by self-interest/reliance based rules. The remainder of this Introduction will explain why these issues are important and also provide a little more detail as to the arguments made about the relationship between ethics and clarity/certainty.

The CRA is an excellent case study on clarity and certainty. It had the specific policy aim to clarify the law, and thereby empower consumers to assert their rights and help businesses

\footnotetext{
${ }^{2}$ Consumer Insurance (Disclosure and Representations) Act 2012, Consumer Contracts (Information, Cancellation and Additional Charges) Regulations 2013, SI/3134, Consumer Protection (Amendment) Regulations 2014, SI/870.

${ }^{3}$ Part 3 covers enforcement powers, private actions in competition law, and letting agents.

${ }^{4}$ Contracts between "traders" and "consumers" as defined in ss. 2 (2)-(3).

${ }^{5}$ See also on delivery and risk (ss. 28-30) and contractually binding information (ss. 12, 37 \& 50).

${ }^{6}$ Dept. of Business, Innovation and Skills (BIS), Enhancing Consumer Confidence by Clarifying Consumer Law (London, 2012), 5.54; Citizens Advice and Oxford Economics, Consumer Detriment (Oxford 2016).

${ }^{7}$ S. Whittaker, "Distinctive Features of the New Consumer Contract Law" (2017) 133 L.Q.R. 47.
} 
and consumers to resolve disputes informally. ${ }^{8}$ This policy agenda was developed over a number of years, ${ }^{9}$ and it is very important. First, it connects to the consumer detriment issue: even if rules offer a reasonable level of protection on paper, consumers will not be empowered to enforce their rights (and detriment will not be reduced), if these rules are unclear and their application unpredictable. Second, if clearer more predictable law aids informal dispute resolution, this may save court time, and spare consumers and businesses the financial, time and emotional costs of litigation. ${ }^{10}$ Third, the recently implemented ADR Directive seeks to improve out of court dispute resolution, e.g. by setting quality requirements for ADR processes, ${ }^{11}$ but such processes involve significant input by parties with limited legal training, so the rules must be easy to find and apply.

Behavioural economics research shows that clearer law is not guaranteed to deliver these benefits. Whether consumers even use law to resolve problems depends on a range of factors: e.g. perceived risks and costs, consumer preferences and biases, and the design of the "choice architecture" (e.g. including websites mapping legal rights) that "nudges" consumers towards using law. ${ }^{12}$ Nevertheless, there is little point in nudging consumers towards legal rights, if these rights are confusing and uncertain: indeed this makes it harder to build a good choice architecture in the first place. So, clear law is at least a necessary part of any strategy that aims to empower consumers, and improve dispute resolution.

Prior to the CRA, B2C contract law was accepted to be unclear and uncertain: ${ }^{13}$ e.g. conformity standards, remedies and unfair terms rules spread over different legislation and the common law; ${ }^{14}$ inconsistent treatment of very similar transactions $;{ }^{15}$ and uncertainty as to what rules applied to $\mathrm{DC} .^{16}$ The key conformity standards, remedies and unfair terms rules are all now in the CRA, ${ }^{17}$ there is greater consistency across transaction types, ${ }^{18}$ and it is now clear what conformity standards and remedies apply to DC. ${ }^{19}$

Obviously various different factors affect legal clarity and certainty. For example, despite the CRA, clarity remains compromised by leaving too many rules "scattered around" elsewhere-e.g. the information and cancellation rights in the Consumer

\footnotetext{
${ }^{8}$ BIS, Enhancing Consumer Confidence, above note 6, 4-10.

${ }^{9}$ E.g. Law Commissions, Unfair Terms in Contracts, 242, 199 (London 2005), BIS, Consolidation and Simplification of UK Consumer Law (London 2010), BIS, Enhancing Consumer Confidence, above note 6.

${ }^{10}$ E.F. Rickett \& G.W. Telfer, International Perspectives on Consumers' Access to Justice (Cambridge 2003).

${ }^{11}$ 2013/11/EU, implemented by The Alternative Dispute Resolution for Consumer Disputes (Competent Authorities and Information) Regulations 2015, SI, 2915/542.

${ }^{12} \mathrm{C}$. Twigg-Flesner, "Does the codification of consumer law improve the ability of consumers to enforce their rights?" in B. Heiderhoff and R. Schulze, Consumer Law and Consumer Behaviour (Baden-Baden 2016), 211. ${ }^{13}$ BIS, Enhancing Consumer Confidence, above note 6.

${ }^{14}$ E.g. conformity in sales (Sale of Goods Act (SGA) 1979, ss. 12-15, 35), work and materials, exchange, hire (Supply of Goods and Services Act (SGSA) 1982, Part 1), hire purchase-HP (Supply of Goods (Implied Terms) Act 1973 (SOGIT)); remedies in sales (SGA, ss. 35 \& 48 A-E), work and materials (SGSA, s. 11M-S), hire and HP (common law affirmation doctrine-Farnsworth Finance Facilities v Attryde [1970] 2 All E.R. 774); conformity of services (SGSA, Part 2); unfair terms (Unfair Contract Terms Act (UCTA) 1977 and Unfair Terms in Consumer Contracts Regulations (UTCCR) 1999).

${ }^{15}$ E.g. cure, price reduction and final rescission remedies existed for sale \& work and materials (SGA, s. 48 AE, SGSA, s. 11M-S), but not for hire, HP, digital content (DC) or services.

${ }^{16}$ R. Bradgate, Consumer Rights in Digital Products (London 2010).

${ }^{17}$ Part 1, Chapters1-3 (goods, DC \& services), Part 2 (unfair terms); \& Sch. 1 for dis-application of SGA, SGSA, SOGIT \& UCTA rules (notes 14-15, above) from B2C contracts, and revocation of UTCCR (note 14).

${ }^{18}$ E.g. cure and price reduction remedies for goods, DC and services (ss. 23, 24, 43, 44, 55 \& 56).

${ }^{19}$ Part 1, Chapter 3.
} 
Contracts (Information, Cancellation and Additional Charges) Regulations, and the remedies for unfair commercial practices in the Consumer Protection (Amendment) Regulations. ${ }^{20}$ However, the focus here is specifically on how clarity and certainty are affected by the ethical underpinnings of the rules. The argument, as stated above, will be that the rules reflecting the need-based ethic usually do more (or at least no less) to enhance clarity and certainty, than rules wired to the self-interest/reliance ethic. The classical position was that certainty in contract law is best achieved by enforcing what is agreed (no more, no less). ${ }^{21}$ However, in his seminal work on Regulating Contracts, Collins argued that it may be important that the agreed terms can be supplemented and/or reviewed by reference to open textured standards. For Collins, these standards promote certainty because they are flexible enough to allow enforcement of what parties actually reasonably expect e.g. based on previous dealings and trade custom..$^{22}$ Key to the argument made below here will be that the outcome-based rules favoured by the need ethic provide greater clarity and certainty because outcome-based rules are the norm for B2C relations and are therefore "reasonably expected" by the parties. So, like Collins, this article employs a "reasonable expectations" concept, but here it is a new reasonable expectations concept, based on the particularities of the $\mathrm{B} 2 \mathrm{C}$ regime. The argument made here also goes beyond this, arguing that outcome (need) based rules often make dispute resolution more predictable (certain), when compared to the focus on business processes favoured by the self-interest/reliance ethic.

\section{Competing Ethics and Levels of Consumer Protection}

This section sets out the key features of the proposed competing ethics framework, and then explains how this framework provides an improved understanding of alternative consumer protection visions. The idea of competing ethics was first highlighted in relation to judicial approaches to general clauses on standard terms and commercial practices. ${ }^{23}$ The question here is how competing ethics might shape consumer protection choices in consumer contract law much more generally. The discussion focuses on legislative design of consumer contract law rules on conformity standards, remedies and unfair terms. Legislative design of such rules has not been covered in previous work, yet these rules are particularly important. It has already been noted just how much consumer detriment is caused by defective goods, services and DC and by unfair terms $;^{24}$ and the law's response to this is encapsulated in its choice of legislative rules on conformity of goods, services and DC, the remedies for breach of these conformity standards, and the rules on unfair terms. So, these rules really do lie at the very core of $\mathrm{B} 2 \mathrm{C}$ contract law. In addition, these contract law rules on conformity, remedies and unfair terms, are strongly representative of consumer law more generally. This is because they also apply in the public enforcement sphere: where breaches of these contractual standards affect the collective interests of consumers, bodies such as the Competition and Markets Authority and local Trading Standards authorities can take action in the form of seeking undertakings and injunctions. ${ }^{25}$

\footnotetext{
${ }^{20}$ Above note 2; and on unclear drafting in the CRA, Whittaker, "Distinctive Features", above note 7, 49-50.

${ }^{21}$ H. Collins, Regulating Contracts (Oxford 1999), 268.

22 Ibid, 271.

${ }^{23}$ C. Willett, "General Clauses", above note 1; and on judicial ethics and general clauses in consumer credit, S. Brown, "Consumer credit relationships - protection, self-interest/reliance and dilemmas in the fight against unfairness (2016) 36 L.S. 230.

${ }^{24}$ Above note 6.

${ }^{25}$ Enterprise Act, 2002, Part 8.
} 
It has long been accepted that contract law is shaped by underlying values, although the appropriate choice of values has remained contested. Here one might mention debates as to the role of "reliance", "expectation", "promise", "efficiency", preservation of long term relationships etc. ${ }^{26}$ For our purposes, the most significant traditional dichotomy is that between ethical positions that support intervention in the relationship, to achieve what is often referred to as a "fair" balance in the parties' interests; and on the other hand, ethical positions supporting what are often called "freedom of contract" values. ${ }^{27}$

In business to business (B2B) contract law, this dichotomy sometimes maps onto the distinction between late $20^{\text {th }}$ century legislative interventions and traditional common law rules. While legislation such as the Unfair Contract Terms Act 1977 might be said to place controls on party freedom (by subjecting exemption clauses to a "fair and reasonable" test), ${ }^{28}$ many B2B common law decisions might be said to reassert traditional freedom of contract values: e.g. by refusing to develop a general principle of "good faith" or by limiting the circumstances in which the penalty clause doctrine can set aside agreed damages clauses. ${ }^{29}$ As common law still plays a much bigger role in B2B contract law than legislation does, it could be said that "freedom" values still play a strong role in B2B contract law.

In B2C contract law, there has been significantly more legislative intervention than in B2B contract law, involving much greater deviation from what is traditionally labelled "freedom of contract", much more focus on achieving what has been called "fairness", than in any part of B2B contract law. For example, the consumer (the perceived weaker party) is protected by cancellation rights, which do not apply in $\mathrm{B} 2 \mathrm{~B}$ contracts; ${ }^{30}$ by non-excludable rights as to the quality of goods-such rights are excludable subject to a reasonableness test, in B2B contracts; ${ }^{31}$ and by controls over terms imposing unfair burdens on the consumer-in B2B contracts, there are only statutory controls over terms exempting liabilities. ${ }^{32}$

Indeed, Brownsword has argued that B2C contract law is no longer "contract" law at allthere being insufficient choice as to the obligations undertaken to talk of a "contract" in the traditional sense-rather it is a form of regulation. ${ }^{33}$ However, it is one thing to say that there is regulation, not contract. The point here is to go beyond this: to show that there are alternative visions as to the degree of regulatory protection that should be provided to consumers. Now, some prior work has focused on the distinction between approaches influenced by values of fairness and values of freedom. ${ }^{34}$ However, in the subsequent paragraphs here it is argued that consumer contract law is better explained by a theoretical framework based on competing ethics of "self-interest/reliance versus need". The idea is that there is a spectrum of ideological or ethical positions that might be taken in consumer

\footnotetext{
${ }^{26}$ See E. McKendrick, Contract Law, $11^{\text {th }}$ edn. (Basingstoke 2015), ch. 1.

${ }^{27}$ P.S. Atiyah, The Rise and Fall of Freedom of Contract (Oxford 1979); C. Willett, Fairness in Consumer Contracts (Aldershot 2007).

${ }^{28}$ S. 11.

${ }^{29}$ Walford v Miles [1992] 2 A.C. 128; Parking Eye Ltd v Beavis [2015] UKSC 67, H. Beale, "Penalty Clauses in English Law" (2016) 24 E.R.P.L 353.

${ }^{30}$ Consumer Contracts etc Regulations, above note 2, and Whittaker "Distinctive Features", above note 7, on these and other provisions evidencing bifurcation in $\mathrm{B} 2 \mathrm{C}$ and $\mathrm{B} 2 \mathrm{~B}$ contract law values.

${ }^{31}$ UCTA, ss. 6 (3) \& 7 (3).

${ }^{32}$ UCTA, Part 1.

${ }^{33}$ R. Brownsword, "Regulating Transactions: Good Faith and Fair Dealing" in G. Howells and R. Schulze, Modernising and Harmonising Consumer Contract Law (Munich 2009), 89-113.

${ }^{34}$ C. Willett, Fairness, above note 27.
} 
contract law. Towards one end of this spectrum, and overlapping with the values of B2B contract law, is an ethic of business self-interest and consumer self-reliance, which provides limited consumer protection. At the other end of the spectrum, is a more protective ethic, prioritising consumer need. Rather than thinking of B2C contract law as being all about "regulation" or "fairness", or even being about a mixture of "freedom" and "fairness", it is better to try to explain it by reference to these competing ethics of self- interest/reliance versus need.

\section{A. Business Self Interest/ Consumer Self-Reliance}

In the context of conformity standards, remedies and unfair terms, it is submitted that business self-interest and consumer self-reliance might be prioritised in the following ways:

The law can minimise the number of conformity standards applicable to businesses, and the remedies available for breach of such standards: so limiting the need for businesses to expend resources on providing remedies (damages, repair, repeat performance etc) to consumers. At the most extreme end of the spectrum here, there would be no mandatory conformity standards or remedies at all. This is resonant of the traditional "caveat emptor" doctrine, with an extremely high degree of self-reliance being required of consumers if they are to protect their interests: so if any standard at all is to apply to the business' performance, consumers must either negotiate for the business to make some express commitment to this effect, find another business that will so commit, or they must insure against the risks.

Continuing with conformity standards and remedies, and still prioritising business selfinterest and consumer self-reliance (but not quite as much as above), the next hypothetical position that might be taken would be to hold that there should indeed be conformity standards and remedies, but that these should be designed to be as generous as possible to businesses. So, there could be a "fault" or "negligence" based, standard, which allows businesses to escape responsibility for defective outcomes, as long as they have exercised a reasonable standard of care in their input or procedure (i.e. in relation to the actions/omissions involved in the process of providing the goods, DC or services). ${ }^{35}$ Here, the need for self-reliance by consumers is not quite as vital as above-some protective norm applies, so there is at least the possibility of a remedy if the outcome is defective. However, if consumers wish to ensure they have a remedy should things go wrong, they must still exercise a fairly substantial degree of self-reliance. They must negotiate for the business to promise to take responsibility for a defective outcome (even where the process was carried out with reasonable care), or find another business who will agree to this, or insure against the risks. In the absence of such "opt-in" measures at the pre-contractual stage, consumers must, at the dispute stage, demonstrate a lack of reasonable care in the business' process.

Turning to the unfair terms rules (i.e. the rules applicable to the terms-usually standard terms-used by businesses in contracts with consumers), it is submitted that these rules can also be designed in ways that promote business self-interest. Again the key is to focus on business procedures: e.g. allowing terms to be very substantively favourable to businesses (and harsh to consumers), so long as the business ensures (this not being especially onerous) that the terms satisfy "procedural" standards (e.g. clarity, prominence and other

\footnotetext{
${ }^{35}$ See, e.g. the choice (Part IV below) in the CRA to adhere to a fault standard for services, although this is not openly expressed as a choice based on values of self-interest/reliance.
} 
forms of transparency). There is again a direct link with consumer self-reliance. If terms need only satisfy procedural standards, consumers who wish to protect their interests, must make a pre-contractual search for substantively harsh terms, then either bargain for their removal, insure against the risks or find a business who does not use such terms. If none of this is possible, other forms of self-reliance are required: consumers must either avoid any risks that lurk in these terms (e.g. if high charges are payable where the consumer acts in a particular way-such as inadvertently exceeding an agreed overdraft-the consumer must try to avoid such actions); or subsequently impugn the legal validity of the terms, by establishing a defect in the business' procedures, e.g. that the terms are insufficiently transparent. ${ }^{36}$

Where consumer contract law reflects the "self-interest/reliance" ethic, there is a high degree of overlap with the values of B2B contract law, which, as indicated above, takes a broadly non-interventionist approach: e.g. limiting control over penalty clauses and eschewing a general principle of good faith.

\section{B. Need}

Moving along the ethical spectrum, it is submitted that it is possible to take a position more focussed on consumer need. The premise is that consumers are especially vulnerable to detriment, and require greater protection than is provided by the above procedural standards i.e. there should be much less emphasis on business self-interest and consumer selfreliance.

The conception of consumer vulnerability has various facets. First, the idea is that if businesses suffer economic losses (e.g. due to the consumer's breach) or do not make the gains they expect, they are often in a relatively strong position to absorb this e.g. through insurance, spreading losses across different divisions of the business, etc. By contrast, consumers, as private citizens, often have limited capacity to absorb economic losses caused by defective goods, services and DC, or detrimental terms. ${ }^{37}$ Also, for consumers, breaches of contract, detrimental terms, etc., may have a serious impact on the private sphere of life: so called "consumer surplus" effects e.g. loss of time, distress, inconvenience in personal lives, the frustration of obtaining no redress. ${ }^{38}$ Businesses are generally less likely to be affected in these ways. ${ }^{39}$ So, from a need-based perspective, account must be taken of the weaker position of consumers as loss bearers.

The above vulnerabilities relate to the adverse impact of poor quality and harsh outcomes. A further facet of the need-based conception of vulnerability is the perception that consumers struggle to exercise self-reliance to protect themselves from these detrimental outcomes. Various reasons can be cited for this. Lack of knowledge, expertise and experience are key factors here. Not being expert, "repeat players" in the business in question, consumers often have limited knowledge or understanding of the risks of products or services failing, or of the risks in standard terms. ${ }^{40}$ This may mean businesses are not

\footnotetext{
${ }^{36}$ See Part IV on the CRA following this approach, although not openly linking it to self-interest/reliance.

${ }^{37}$ C. Willett, Fairness, above note 27.

${ }^{38}$ C. Willett, "General Clauses", above note 1, 420, and for recent re-affirmation of this problem, particularly in relation to lost leisure time and emotional costs, Citizens Advice and Oxford Economics, Consumer Detriment, above note 6 , chs. $5 \& 7$.

${ }^{39} \mathrm{C}$. Willett, ibid.

${ }^{40}$ J. Wightman, "Beyond Custom: Contracts, Context and the Recognition of Implicit Understandings" in D. Campbell, H. Collins and J. Wightman, Implicit dimensions of Contract (Oxford 2003) ch. 5; C. Willett, ibid.;
} 
placed under sufficient competitive pressure to offer guarantees as to high quality outcomes and to provide standard terms that take account of consumer interests. Even if consumers are aware enough to seek to bargain for such outcomes, they will struggle to be successful. Individual consumers are not usually important enough to businesses to place them in a strong bargaining position. Also, because they are not repeat players when it comes to business negotiation, consumers often lack the sophistication and experience of businesses. ${ }^{41}$ This will usually place the consumer at a disadvantage when seeking to negotiate resolution of a dispute. This disadvantage will be all the greater the more that the actual legal standards favour the business, e.g. where businesses escape responsibility for defective outcomes so long as they have exercised reasonable care in their processes, or are permitted to use terms detrimental to consumers so long as they make the terms transparent.

So, from a need-based perspective, paying attention to the above consumer vulnerabilities, a key priority of the law should be to protect consumers from detriment. What are the implications of this for rules on conformity standards, remedies and unfair terms?

Conformity standards should be strict liability in nature: businesses to be responsible for defective outcomes, even if they have exercised reasonable care in their procedures (as long as this would not overburden businesses, e.g. where achieving outcomes is too unpredictable). As indicated above, from a need-based perspective, poor quality outcomes are perceived to have a particularly harmful effect on consumers. In addition, consumers are considered to have limited knowledge, experience, skill and power, and so will find it very difficult (i) to win arguments (especially out of court) about whether businesses have exercised reasonable care in their processes (particularly, as we shall see below, where machinery or technology is involved); or (ii) to bargain at an earlier stage for businesses to voluntarily agree to guarantee that the outcome will not be defective.

Also, if guided by a need ethic, the remedies for breach of conformity standards should be designed to take account of consumer vulnerabilities. So, the remedies should prevent detriment being exacerbated at the dispute stage: and we shall see below that cure remedies may be more effective in this regard than damages.

As for the design of rules for contract terms, from a need-based perspective, it should not be sufficient for the terms to be transparently presented during the pre-contractual process. In addition, these terms - the outcome or result of the pre-contractual process - should not be substantively harsh on consumers. This again reflects the concern to ensure consumer protection against detrimental outcomes (here, substantively harsh terms), the idea being that this can rarely be achieved by self-reliant consumer action. The view from a need-based perspective would be that even if terms are transparent, this is of limited practical use in helping consumers to protect their interests. The need-based argument for this would run as follows: Pre-contractually, consumers will often not have time to read the ancillary terms; but will focus on "core" issues: the main goods, services or DC, the main price. ${ }^{42}$ Even if they read the standard terms, consumers will struggle (in particular due to limited experience) to

and for recent support from behavioural economics, F. Esposito, “A Dismal Reality: Behavioural Analysis and Consumer Policy", (2017) 40 Journal of Consumer Policy 1.

${ }^{41}$ R. Brownsword, Contract Law: Themes for the Twenty-First Century (Oxford 2006), 79-85 and C. Willett, Fairness, above note 27, 39-46.

${ }^{42}$ C. Willett, "General Clauses", above note 1, 423-4. 
estimate how likely it is that the circumstances the terms deal with, will become relevant (e.g. as we shall see below at Section IV, it may be very hard to estimate whether contingent charges will become payable). This, in turn, makes it unlikely that consumers will make purchasing choices based on the standard terms, and consequently also unlikely that businesses will be forced to compete to offer terms that do not cause consumer detriment. ${ }^{43}$ Being unaware of the existence of prejudicial terms, consumers will not typically insure against relevant risks, or bargain for removal of the terms - and anyway their weaker bargaining position would usually make such bargaining unsuccessful. If there is scope for consumers to take action to protect their interests later, e.g. avoiding high charges by staying within an agreed overdraft, they will often not do so due to understandable factors such as everyday pressures, forgetfulness etc. Finally, if a dispute arises, there is little consumers can do, if all the business need do to win, is show that the term is transparent.

\section{No claim as to the normative supremacy of either ethic}

The competing ethics of self-interest/reliance and need represent different visions of the ideal market order: of what best serves consumer, business and societal interests, and no claim is made here that one vision is "better" as such. Certainly, the need ethic aspires to set higher levels of protection, but this does not, per se, make it superior. One view is that the self-interest/reliance ethic is superior because it is less paternalistic, while it might be responded that a degree of paternalism is required to protect the (weaker) consumer. These alternative views of course do little more than reflect the basic values inherent in the respective ethics. Equally both ethics can find support in economic analysis. Classical economics tends to assume the less regulated choices favoured by the self-interest/reliance ethic to be rational and therefore to produce efficient outcomes; while modern behavioural economics seriously doubts such assumptions of rationality - and therefore supports the notion that consumers often cannot be expected to exercise significant self-reliance. ${ }^{44}$

\section{Beyond Freedom and Fairness}

While no claim is made that one of the ethics is normatively superior, what is claimed is that the "self-interest/reliance versus need" framework promoted here provides a much improved theoretical framework for consumer contract law. As indicated above, one way that contract law theory has previously explained regulatory choices is through a dichotomy of "freedom of contract" (basing rights and obligations on the agreement of the parties - no more, no less), and "fairness" (basing rights and obligations on balancing the interests of the parties). ${ }^{45}$ Certainly in broad terms, the self-interest/reliance ethic might often be equated with freedom of contract (parties "free" to pursue their own interests and make self-reliant choices); while the need ethic might often be equated with fairness (it being arguably "fair" to balance the interests so as to protect the weaker party).

However, the self-interest/self-reliance versus need framework is arguably a more illuminating way of conceptualising the important regulatory choices: being more nuanced and precise (than a freedom versus fairness framework) as to the competing values and choices about levels of protection. First, "self-interest/reliance" is more determinate than the

\footnotetext{
${ }^{43}$ C. Willett, "General Clauses", ibid, 423-4; generally on the limits of protection via transparency, G. Howells, "The Potential and Limits of Consumer Empowerment by Information" (2005) 32 (3) J. Law Soc. 349.

${ }^{44}$ F. Esposito, "A Dismal Reality", above note 40.

${ }^{45}$ C. Willett, Fairness, above note 27.
} 
notion of "freedom". Rather than referring simply (and rather vaguely) to "freedom" (or the similar alternative, "autonomy"); the focus is specifically on business freedom (autonomy) to pursue self-interest, and consumer freedom (autonomy) to exercise self-reliance. This also draws a clear line between competing ethics. Self-interest/reliance cannot really be confused with the need ethic, yet "freedom" is sometimes understood to mean something similar to the need ethic: the argument being that information and bargaining weaknesses mean consumers have no "real" freedom, so when the law imposes outcome-based standards to protect consumers, it is actually imposing the standards consumers would choose if they were "really" free. ${ }^{46}$

The need ethic is linked to the sociological concept of "need rationality"77 and, as indicated, can be equated broadly with the notion of "fairness" as interest balancing: Protecting weaker parties (following the need ethic) can be viewed as the "fair" way to balance the parties' interests. At the same time, the need ethic (like the fairness ethic) does actually balance interests: The need ethic may favour strict liability standards (to protect the consumer as weaker party), but these standards still take into account business interests. For example, the strict liability satisfactory quality standard applicable to goods and DC does not involve "absolute" liability, rather businesses can reduce the level of quality that is viewed as "satisfactory" by how they describe and price goods. ${ }^{48}$

However, these similarities notwithstanding, the need ethic is more nuanced and precise than the fairness concept. Whatever interest balancing may be done, it is very clear that the priority is consumer "need", i.e. to protect consumers from the consequences of their vulnerabilities. In contrast, the more generic "fairness" concept does not make it sufficiently clear that the priority is to protect the consumer as the weaker party, and it allows scope for it to be argued that it is "fair" to prioritise business self-interest and consumer self-reliance. For example, the traditional distinction made between "procedural fairness" and "substantive fairness" arguably glosses over the difference emphasised here between selfinterest/reliance values of process/input based ("procedural") standards and the more needbased values of outcome-based ("substantive") standards. ${ }^{49}$

\section{Need-based Rules: High Level of Protection, Improving Clarity and Certainty}

This Part begins to show how the ethics of need and self-interest/reliance are reflected in the actual rules. It highlights rules that are underpinned by the need ethic and provide a reasonably high level of protection (while Part IV will highlight rules underpinned by the selfinterest/reliance ethic and setting a lower level of protection). This Part also begins to address the other key research question: how the competing ethics affect legal clarity and

\footnotetext{
${ }^{46}$ C.R. Sunstein and R.H. Thaler "Libertarian Paternalism Is Not an Oxymoron" (2003) 70 The University of Chicago Law Review 1159.

${ }^{47}$ T. Wilhelmsson, Critical Studies in Private Law (Dordrecht, 1992).

48 e.g. CRA, s. 9 (2) (a))

${ }^{49}$ P.S. Atiyah, The Rise and Fall and C. Willett, Fairness, both above note 27 on procedural and substantive fairness; and C. Willett, "General Clauses", above note 1, on non-protective judicial interpretations of the "fairness" test applicable to contract terms. Note also the contrast between the "need" ethic and the "inequality of bargaining power" doctrine suggested for the common law but rejected in National Westminster Bank plc $v$ Morgan [1985] AC 686: the focus on "bargaining power" could suggest a concern only with procedural (process/input) problems and therefore something more in tune with the self-interest/reliance ethic.
} 
certainty. It demonstrates a strong link between the need ethic and legal clarity and certainty.

\section{A. New DC Conformity Standards:}

The DC market is enormous and constantly expanding. Even in 2012, 40\% of home internet connections were used for playing games and downloading music or video. ${ }^{50}$ Yet, prior to the CRA, there was enormous confusion as to what conformity standards applied to DC. There have long existed outcome-based (strict liability) terms as to quality, fitness etc in contracts for the supply of goods. ${ }^{51}$ Prior to the CRA, where DC was supplied on a tangible medium, it could (although this was not completely clear) be classified as goods, and therefore be covered by these terms. ${ }^{52}$ However, where there was no tangible medium, it was unclear whether the contract was "sui generis", containing a common law implied (outcome-based) term of reasonable fitness for purpose,${ }^{53}$ or a contract for services, ${ }^{54}$ in which case there would be a statutory implied term of reasonable care and skill (a fault standard). ${ }^{55}$ There is evidence that quality problems with DC cause significant consumer detriment: ${ }^{56}$ and apparently this confusion was a real obstacle to consumer redress. ${ }^{57}$

The CRA addresses this problem. Where data is "produced and supplied in digital form" (i.e. no tangible medium), this is classed as a distinct type of contract for "DC" ${ }^{8}$ and in such contracts (following the approach in goods contracts) the CRA imposes (strict liability, outcome-based) terms on quality, fitness for purpose, description and right to supply. ${ }^{59}$ These new rules are underpinned by a need-based ethic, and will normally result in a reasonably high level of consumer protection. The focus is on whether there has been a defective outcome (DC of poor quality, not fit for purpose etc). Sellers cannot escape responsibility based on their procedures, i.e. based on having exercised reasonable care in the selection or supply of the DC. ${ }^{60}$ If a reasonable care (fault) based standard had been chosen, sellers would have escaped responsibility on this basis: typically not being liable where standard business practice had been followed. ${ }^{61}$ This would have set a low level of consumer protection, given that (as with goods) there is often a producer, who supplies the DC under a contract to a retailer, who subsequently sells under a separate contract to the consumer. Just as with goods, faults in DC usually emanate from the production process, but retailers cannot be expected to open and check DC before selling it to consumers, and even if they did check it, faults are often latent, i.e. not obvious to the retailer. So, it would often be very difficult to show that the retailer had not acted with reasonable care. With the

\footnotetext{
${ }^{50}$ BIS, above note 6,138 .

${ }^{51}$ SGA, above note 14- for B2C contracts now CRA ss. 9-18.

${ }^{52}$ International Computers Ltd v St Albans District Council [1996] 4 All E.R. 481 and SAM Business Systems v Hedley (unreported).

${ }^{53}$ Beta Computers (Europe) Ltd v Adobe Systems Ltd [1996] S.L.T. 604; but now Software Incubator Ltd v Computer Associates [2016] EWHC 1587 (QB), where software supplied alone was viewed as goods under the Commercial Agents (Council Directive) Regulations 1993.

${ }^{54}$ Salvage Association v CAP [1995] F.S.R. 654.

${ }^{55}$ SGSA, s. 13-for B2C contracts, now CRA, s. 49.

${ }^{56}$ BIS, Enhancing Consumer Confidence, above note 6, 7.44-5.

${ }^{57}$ Ibid, 7.46-59, R. Bradgate, Consumer Rights in Digital Products above note 16.

${ }^{58}$ S. 33.

${ }^{59}$ ss. 34-36, 41, and ss. 39-40 for other rules specially designed for DC.

${ }^{60}$ These standards cannot be excluded by businesses' standard terms-s. 47 .

${ }^{61}$ Bolam v Friern Hospital Management Committee [1957] 2 All E.R. 118, , on fault in common and civil law systems, S. Grundman, "The Fault Principle as the chameleon of Contract Law: A Market Function Approach" (2009) Michigan Law Review, 1583, 1593-4.
} 
chosen outcome-based standards, there is a breach (and a remedy), so long as it can be shown that the DC is defective in terms of quality, fitness etc.

These reforms demonstrate the need ethic in action, setting a high level of protection, with outcome-based conformity standards. However, the reforms are also vital in helping to answer the question as to the relationship between competing ethics and legal certainty and clarity. The need-based DC regime contributes strongly to the CRA's clarification policy goal: enhancing certainty and predictability and reducing complexity. First, there is improved certainty because it is now clear exactly what standards apply. Behavioural science research demonstrates the importance of clear "choice architecture" in influencing consumer behaviour, ${ }^{62}$ and this obviously includes clarity as to what the rules actually are. Second, the need-based regime arguably enhances clarity and certainty by creating greater consistency and therefore better reflecting the parties' reasonable expectations. The point is that the DC regime is now consistent with the regime for goods contracts, i.e. the same (outcome-based) standards apply. Now, one might argue that to achieve clarity and certainty, all that matters is that rules are expressed clearly and can be applied in a predictable way. However, clear expression and predictable application notwithstanding, there is arguably unnecessary complexity and confusion if two very similar transactions are regulated by conceptually different rules. Indeed, consumers and businesses may expect goods and DC (which are likely to appear very similar to the parties, both often mass produced, and both often supplied together) to be subject to similar standards. ${ }^{63}$ If different standards apply, this fails to reflect reasonable expectations-causing confusion and undermining the clarity of the "choice architecture" that behavioural science indicates is important to empowering consumers to enforce rights. ${ }^{64}$ Collins has already used the idea of reasonable expectations to challenge the traditional view that simply enforcing what is agreed is the best way to foster certainty. He showed that open textured supplementation and review standards may promote certainty by providing the flexibility to enforce what parties actually reasonably expect, based on the long term business relationship, customs and making the deal work for both parties. ${ }^{65}$ Here, the "reasonable expectations" concept is developed in another way, to support the argument that in $\mathrm{B} 2 \mathrm{C}$ relations, the need ethic may foster clarity and certainty: the case (to recap) being that the DC need-based rules focus on outcomes, that this is the norm for similar transactions (i.e. goods) and is therefore what is "reasonably expected" by the parties, which in turn makes the regime clearer and more certain for the parties.

Finally, the outcome-based standards provide certainty, because it is normally reasonably predictable how they will apply to a dispute. The focus is on the final state of the DC received by the consumer. Especially with new DC, it should usually be reasonably clear whether it is of satisfactory quality, fit for purpose, etc. The importance of this should not be underestimated when it comes to empowering consumers to utilise their legal rights. Recent behavioural science work emphasises that consumers are loss averse and that perceived costs and risks (increased by unpredictable standards) reduce the likelihood that they will make use of law. ${ }^{66}$ Compared to the chosen outcome-based standards, a fault standard often involves much more complex arguments, e.g. as to what quality control processes

\footnotetext{
${ }^{62}$ C. Twigg-Flesner, "Does the codification", above note 12.

${ }^{63}$ R. Bradgate, Consumer Rights in Digital Products, above note 16, 40-1.

${ }^{64} \mathrm{C}$. Twigg-Flesner, "Does the codification", above note 12.

${ }^{65}$ H. Collins, Regulating Contracts, above note 22, 271.

${ }^{66}$ C. Twigg-Flesner, "Does the codification "above note 12; European Commission, Behavioural Research (Brussels 2016).
} 
were set up and followed (or not) by the supplier: making it harder to predict the result in any given case (see Part IV below).

The DC example is an excellent illustration of need-based rules improving protection, and it also demonstrates the strong link between the need ethic and clarity/certainty. We now turn to important (need-based) remedies that also improve protection, clarity and certainty.

\section{B. Cure Remedies}

For over a decade, in sale and work and materials contracts, consumers have had remedies of free repair or replacement of non-conforming goods: introduced to implement the Sale of Consumer Goods Directive (SCGD) ${ }^{67}$ The CRA extends these remedies to hire, hire purchase (HP) and DC contracts, where the goods or DC do not conform, e.g. where they are in breach of the terms as to quality, fitness etc, or express terms. ${ }^{68}$ "Repair" means bringing the goods or DC into conformity with the contract; ${ }^{69}$ "replacement" is not defined, but clearly involves replacement of the overall thing bought-new car, download, app etc.

The CRA also introduces a cure remedy in services contracts, providing that where the service does not conform, the consumer can demand free repeat performance to bring the service into conformity. ${ }^{70}$ A service does not conform when there is breach of the s. 49 term, which requires the service to be carried out with reasonable care and skill, or of a term arising under s. 50 (based on pre-contractual information provided by the supplier). ${ }^{71}$

These cure remedies are available in most cases. While the supplier can refuse to repair or replace goods or DC, or to repeat perform a service, if the requested remedy is impossible ${ }^{72}$ this will be relatively rare. Goods or DC might be beyond repair, but then normally a replacement will be possible, unless the item is unique; while most services can be repeated. Repair of goods or DC can be refused if it is disproportionately expensive compared to replacement, and vice versa, ${ }^{73}$ but this "disproportionality" test does not apply to one cure remedy if the other one is impossible. ${ }^{74}$ Even when the disproportionality test does apply, and one cure remedy is found to be disproportionately expensive compared to the other, this other cure remedy is available, even if it is itself quite expensive: there is no provision allowing the business to refuse repair or replacement on the grounds that it is disproportionately expensive compared to price reduction, refund or some other remedy. (Such a comparison was allowed under the previous regime, but this was an incorrect implementation of the SCGD. ${ }^{75}$ ) Therefore, with goods and DC, consumers are always entitled to one of the two cure remedies, as long as they are not both impossible. With services, there is no proportionality defence at all, so repeat performance is guaranteed, unless impossible. Of course, ultimately cure can only be enforced by an order of specific performance (SP), and the court powers provision arguably allows a degree of discretion,

\footnotetext{
67 99/44/EEC, art 3.

${ }^{68}$ Ss. 19, 23, 42 \& 43; note the separate 30 day short term rejection right (s. 22).

${ }^{69}$ Ss. $23(8) \& 43(8)$.

${ }^{70}$ Ss. $54 \& 55$.

${ }^{71}$ S. $54(2)$.

${ }^{72}$ Ss. 23 (3) (a), 43 (3) (a) \& 55 (3).

${ }^{73}$ Ss. 23 (3) (b) \& 43 (3) (b).

${ }^{74}$ Case 65/09, Gebr Weber GmbH v Wittmer andCase 87/09, Ingrid Putz v Medianess Electronics GmbH, interpreting SCGD, art 3, from which the "disproportionality" test derives.

${ }^{75}$ E.g. (the repealed) SGA, s. 48B, see Gebr Weber/Ingrid Putz ibid.
} 
providing that the court "may" (not "must" or "will") award SP. ${ }^{76}$ However, this is surely not intended to allow courts to take the traditionally very restrictive approach to SP-routinely refusing it and viewing damages as an adequate alternative. ${ }^{77}$ Such an approach would undermine the whole point of including cure remedies, and probably also fail to implement art 3 of the SCGD, which generally requires repair and replacement to be provided in sales contracts, as long as the impossibility and disproportionality "defences" do not apply. ${ }^{78}$ So, SP can probably only be refused in extreme cases: i.e. where the non-conformities are minor and SP would involve extreme costs or time commitments for the business. ${ }^{79}$

The routine availability of cure is a fundamental change for English contract law. Damages have traditionally been the primary remedy for breach. ${ }^{80} \mathrm{SP}$ was always theoretically available as a remedy to support non-performance of the primary obligations. However, as indicated above, SP was never routinely granted, the key justification being that damages offer an "adequate" substitute: ${ }^{.1}$ that the party affected by the breach can obtain cure from a third party and recover damages (from the breaching party) to cover the cost of this cure. Yet, from a need-based perspective, this is often not adequate at all.

Certainly consumers may often be content to obtain cure from a third party, but sometimes this may cause significant consumer detriment, and generate undesirable legal and practical complexities. First, there is the time, inconvenience and expense involved in finding and paying a third party to cure the breach: and payment may be a particular problem with expensive services such as building, especially as the consumer has already paid the original supplier. Then, once the third party has effected cure, the consumer must return to the original supplier, and potentially face arguments about how much of what has been paid to the third party can be recovered in damages: there may, e.g. be legal arguments as to whether the consumer has paid too much to the third party and thereby failed to mitigate his losses. Also, third party involvement could generate arguments about causation, e.g. where the third party makes things worse..$^{82}$ All of these problems will be greater with complex and expensive goods, DC or services (e.g. building): adding to the detriment already caused by the breach, potentially meaning further inconvenience and economic detriment.

The cure remedies protect consumers from these problems and provide a further example of the need ethic in action. However, the cure remedies also further emphasise the link between the need ethic and clarity/certainty. First, as with the DC reforms, the need-based cure regime improves clarity and certainty by improving consistency between similar transactions and arguably therefore better reflecting the parties' reasonable expectations. It is less confusing if there is a common set of cure remedies, whatever the precise nature of the supply of goods contract, and also for DC and services. It is complex and confusing if (as was the case prior to the CRA) consumers have cure remedies against those who sell goods

\footnotetext{
${ }^{76}$ S. $58(2)$

${ }^{77}$ Beswick v Beswick [1968] AC.

${ }^{78}$ Gebr Weber, above note 71, and Whittaker, "Distinctive Features", above note 7, 64.

${ }^{79}$ See Whittaker ,"Distinctive Features", ibid., 66 on the alternative of refusing SP, but granting damages in lieu under s. 50 of the Senior Courts Act 1981, to cover even disproportionate costs of third party cure.

${ }^{80}$ The damages remedy is preserved by the CRA: ss. 19 (11) (a), 42 (7) (a) \& 54 (7) (a).

${ }^{81}$ Beswick v Beswick above note 77, and explaining the contrary civil law tradition, Whittaker, "Distinctive Features", above note 7, pp. 62-3.

82 On the duty to mitigate losses and the need to establish the causal link between breach and loss: Thai Airways International plc v KI Holdings Co Ltd [2015] EWHC 1250 (Comm), H.L.A. Hart and T. Honoré, Causation in the Law (Oxford 1985), ch. XI.
} 
or supply them under a work and materials contract, but not against other suppliers of goods or DC, or against service suppliers. Whether the transaction is technically sale, work and materials, hire or HP, (defective) goods have been supplied. DC will appear very similar to most-often being mass produced just like goods, and being supplied along with or in close proximity to, goods, e.g. the supply of a phone, followed by software such as an app.

Services will also often be supplied along with goods, e.g. car repairs which involve the supply of parts. It may well be contrary to the parties' reasonable expectations and confusing, if transactions that appear very similar and that often occur together are in fact regulated by different standards. ${ }^{83}$ This conclusion is supported by the behavioural science research demonstrating the importance of good choice architecture. ${ }^{84}$

Second, as with the new DC conformity standards, ${ }^{85}$ the cure remedies provide greater certainty in the form of greater predictability. If consumers use these remedies against the original supplier, this avoids the abovementioned complex and unpredictable disputes that may arise if consumers must rely on cure by third parties.

So, similarly to the DC conformity standards, the need-based cure remedies improve protection, and they further demonstrate the link between the need ethic and certainty/clarity.

\section{$D$ Beyond Freedom and Fairness}

The DC and cure examples also confirm that the competing ethics framework is more nuanced and precise than the traditional "freedom versus fairness" framework, in highlighting the values involved. When first explained above, the need ethic was shown to be concerned with protecting consumers from their vulnerabilities. Here we have seen this manifest, e.g., in cure remedies, which protect consumers from the inconvenience, expense and complex arguments that the "third party cure/damages" option may involve, recognising that consumers need this protection due to their more limited bargaining power, experience and loss bearing abilities. By contrast, it is not so obvious that the more general "fairness as interest balancing" ethic would take this approach. It might do. It could be said to be "fair" to recognise consumer vulnerabilities in the way the cure remedies do. But "fairness" is vague and can be understood in different ways. It might be argued to be "fair" to place more emphasis on business self-interest, making it "fair" for breaching businesses to refuse to cure, this being more efficient and convenient for them. On the consumer side, it might be argued that the theoretical availability of cost of cure damages is "fair", or as the orthodox position has it, "adequate" for consumers, i.e. "fairness" elides with the opportunity for consumers to exercise self-reliance to recover damages.

\section{Self-Interest/Reliance Based Rules: Lower Level of Protection, Hindering Clarity and Certainty}

This section highlights the ethical tension at the heart of consumer contract law: showing how (in contrast to the above DC and cure rules) the CRA also contains rules underpinned by the self-interest/reliance ethic and providing less protection. It also shows that when it

\footnotetext{
${ }^{83}$ Above notes 63-5 and related text, particularly on how this argument develops prior thinking on reasonable expectations and clarity/certainty.

${ }^{84}$ C. Twigg-Flesner, "Does the codification", above note 12; cf. Whittaker, "Distinctive Features", above note 7 , 63 on the inconsistency of SP still not being available for breach of primary obligations, e.g. failure to deliver.

${ }^{85}$ See above note 66 and related text.
} 
comes to achieving clarity/certainty, the self-interest/reliance based rules are either worse, or at least no better than, the need-based alternatives.

\section{A. Retention of the Fault Standard for All Services}

In the services sector, poor performance causes considerable consumer detriment. In the year to April 2011 the government's Consumer Direct Helpline received 70,000 complaints about building and home improvement contracts alone, with very significant attendant financial detriment, distress and inconvenience, while in one quarter alone of 2014-15, Citizens Advice Bureaux received 14,535 enquiries on home improvement contracts ${ }^{86}$

It was shown above that the new repeat performance remedy for services is inspired by the need ethic. However, consumers can only access this remedy if there is a breach of the relevant conformity standard, so all is dependent on what this standard is and how easy or hard it is to establish a breach of it. The previous regime contained an implied term that a business must carry out a service with reasonable care and skill. ${ }^{87}$ This covered (i) "pure" services, e.g. advice, education, etc, ${ }^{88}$ and (ii) services applied to property or DC already owned by the consumer, e.g. repair, cleaning, storage of goods, cloud storage of DC. ${ }^{89}$

Prior to the CRA, there was a proposal to apply a "satisfactory quality" standard to this second category of services..$^{90}$ While it was the service (the business' input) that was to have been of satisfactory quality, key to assessing this would have been the "outcome" of the service, i.e. the condition of the goods or DC after services like repair, cleaning or storage. ${ }^{91}$

Ultimately, the decision was taken to retain the reasonable care (negligence based) standard for all services and this rule is copied over into the CRA from the SGSA. ${ }^{92}$ It was argued by some businesses, and accepted by the government, that services are too intangible, complex and subjective to allow measurement of whether an outcome is of "satisfactory quality". ${ }^{93}$ This may be true in relation to 'pure' services. So, with education, what is the 'outcome'? The materials provided? How they are explained? Both? How students translate this into exam performance?

Yet, with services related to consumer property and DC, there is an obvious tangible outcome that can be assessed: i.e. the final state of the goods/DC, after the service is carried out. There are also objectively verifiable ways of measuring quality: whether the goods or DC have been damaged while being stored, whether they have been reasonably well repaired, cleaned, etc. Certainly, consumers may have differing, subjective, expectations on such issues, but the same is true of goods, and outcome-based quality

\footnotetext{
${ }^{86}$ BIS, Consumer Protection Partnership Priorities (London 2015), 1.44-5.

${ }^{87}$ SGSA 1982, s. 13.

${ }^{88}$ Also where tangible things like semen are supplied, but courts classify this as a services contract, because strict liability is considered inappropriate in policy terms (Kobe Ter Neuzen $v$ Korn (1995), 127 DLR (4 $\left.{ }^{\text {th }}\right)$ 577).

${ }^{89}$ If goods or DC are also supplied (e.g. car parts, paint) these are covered by the outcome-based terms on quality etc (CRA, ss. 8-18); similarly where a business sells and installs goods (s. 15 (1) (c)).

${ }^{90}$ BIS, Enhancing Consumer Confidence, above note 6, at 115-20, 183-5

${ }^{91}$ I. Ramsay, Consumer Law and Policy (Oxford 2012), 567, supporting an outcome-based standard in such cases.

92 S. 49

${ }^{93}$ BIS, Consumer Rights Bill: Statement on Policy Reform and Responses to Pre-Legislative Scrutiny (London 2014), 23-6.
} 
standards have long been effectively used in this context. ${ }^{94}$ This is managed by applying both objective criteria (what "a reasonable person" regards as satisfactory, taking into account fitness for common purposes, etc.), and subjective expectations, those raised e.g. by the "description" or the "price". ${ }^{95}$ These same criteria were contained in the proposed outcome-based standard for services related to consumer property/DC. ${ }^{96}$ Finally, addressing the argument as to complexity, it is not significantly more complex to apply these criteria to the condition of goods/DC after a service, than to apply them to goods or DC supplied by the business-especially as goods supplied by the business are often second hand goods (cars being the classic example), where account must be taken of such varied factors as the age of the goods, the price paid, description given etc.

Arguably, then, the proposed outcome-based standard would have been perfectly workable. ${ }^{97}$ The chosen negligence-based standard certainly reflects the selfinterest/reliance ethic. It is not enough for consumers to establish a defective outcome. The business usually escapes responsibility unless the consumer demonstrates that the business' processes did not follow standard business practice. ${ }^{98}$ Yet, from a need-based perspective, this expects very significant consumer self-reliance, given their limited knowledge and experience of such matters, and their limited bargaining expertise and power. The other option is for consumers to exercise earlier self-reliance and to persuade the business pre-contractually either to make an express contractual promise to achieve a satisfactory outcome, or even to make the less formal commitments that might lead a court to find a common law implied term of fact that the outcome will be reasonably fit for purpose.$^{99}$ From a need-based perspective, it is unrealistic to expect consumers to extract such commitments, given their limited knowledge, experience and bargaining strength.

Overall then, the fault standard provides limited consumer protection. Where consumers cannot establish fault in the business' process, potentially high levels of consumer economic detriment will go un-remedied; particularly with high economic value contracts for services related to consumer property, e.g. home improvement. ${ }^{100}$ There may also be significant consumer surplus losses, e.g. the upheaval and stress when homes cannot be used normally due to poor home improvement work. The proposed outcome-based standard was grounded in the need ethic, and more likely to ensure consumer protection. Under this standard, there would normally be a breach (and a remedy) where the outcome is defective: e.g. if goods are damaged after repair or storage, if a house extension is defective.

The chosen input/process based standard also undermines clarity and certainty. First, there is the complexity and possible confusion caused by differing standards for goods/DC on the one hand (outcome-based), and services on the other (input/process based). As already discussed above, the existence of different standards increases complexity and

\footnotetext{
94 CRA, ss. 9-11.

${ }^{95}$ CRA, s.9.

96 Above note 90.

${ }^{97}$ On outcome-based standards for services related to property, in German and French law, H. Beale, B. Fauvarque-Cosson, J. Rutgers, D. Tallon and S. Vogenauer, Cases and Materials on Contract Law, $2^{\text {nd }}$ edn., (Oxford 2010), 721-727.

${ }^{98}$ Bolam v Friern Hospital Management Committee, S. Grundman, "The Fault Principle", above note 61.

${ }^{99}$ Independent Broadcasting Authority v EMI \& BICC (1980) 14 BLR 1, and see potential liability under CRA, s. 50, when a satisfactory outcome is indicated pre-contractually, but this is entirely voluntary.

${ }^{100}$ Above note 86.
} 
complicates the "choice architecture" consumers. ${ }^{101}$ Things are particularly confusing and contrary to reasonable expectations where services are supplied along with goods or DC, e.g. brake-pads supplied and fitted as part of a car service. Here the consumer finds that the business is strictly responsible if the brake-pads are defective, but only liable on proof of negligence if the car is damaged by the repair. ${ }^{102}$

So, just as need-based DC rules and cure remedies are more conducive to clarity and certainty because they create greater consistency and reflect reasonable expectations (above), we find here that self-interest/reliance-based rules compromise clarity/certainty by causing inconsistency and undermining reasonable expectations. However, there is a second point. Just as need-oriented DC and cure rules foster clarity/certainty by being predictable in their application (above), the opposite appears to be the case with some rules grounded in the ethic of self-interest/reliance. The input/process (negligence) based standard for services may cause complex disputes with unpredictable results, especially where services involve machinery or technology: as is common with services applied to consumer property or DC, e.g. car repairs, home improvement and internet services. ${ }^{103}$ The business may argue that some such factor has caused the unsatisfactory outcome: e.g. the car engine problem not diagnosed due to the defective testing machinery. A process based standard considers whether the business has followed standard business practice in terms of checks, tests etc. on the machinery or technology. Suppliers may produce a 'paper trail' showing that all generally accepted procedures were followed. It may be very time consuming and difficult for consumers to contest such defences. This may make it particularly difficult to resolve matters efficiently out of court; and the outcome of the disputewhether in or out of court - may be hard to predict. As noted several times above, ${ }^{104}$ behavioural research shows that perceived costs and risks (increased by complex and unpredictable standards) reduce the likelihood that consumers will rely on their legal rights. It would entirely miss the point to respond that consumers may benefit from reversal of the burden of proof under the res ipsa loquitur (RIL) doctrine: the defective outcome leading the court to infer negligence in the business' process. The whole point of the CRA's clarity policy agenda is to empower consumers to enforce rights and obtain redress out of court, ${ }^{105}$ where RIL will not help.

The proposed (need-based) standard would have avoided complex arguments about negligence. The focus is not on business processes, but simply on the quality of the outcome received- whether, e.g., goods are reasonably well repaired, cleaned etc; whether DC is damaged or lost during cloud storage.

The approach to the services conformity standard shows the ethical tension running through consumer contract law, and the consequences for protection and clarity/certainty. Here, in contrast to the DC and cure rules, the ethic is one of self-interest/reliance: producing a low level of protection and also undermining clarity/certainty. We now turn to another example of this.

\footnotetext{
${ }^{101}$ C. Twigg-Flesner, "Does the codification", above note 12.

${ }^{102}$ BIS, Enhancing Consumer Confidence above note 6, 124, on this conflicting with reasonable consumer expectations.

${ }^{103}$ Acknowledging this, BIS, Enhancing Consumer Confidence above note 6, 113, and on the complexities of negligence, S. Hedley, "Making Sense of Negligence" (2016) 36 L.S. 491-512, especially p. 493.

${ }^{104}$ E.g. European Commission, Behavioural Research (Brussels 2016), above note 66.

${ }^{105}$ BIS, Enhancing Consumer Confidence, above note 6, 4-10.
} 


\section{B. The price term exemption}

CRA Part 2 contains the unfair contract terms regime, unifying the previously overlapping regimes from UCTA and UTCCR. ${ }^{106}$ The new regime does add new protections: individually negotiated terms are now covered by the test of unfairness, ${ }^{107}$ and even if the parties have not raised the issue, courts must now review the fairness of a term if they have the appropriate factual and legal material. ${ }^{108}$ However, the focus here is on the choice made under the CRA to interpret the "price exemption" broadly: this reflecting the selfinterest/reliance ethic, limiting consumer protection against non-essential charges, and undermining clarity/certainty.

Now, before proceeding further, one key clarification should be made. The CRA uses the language of "fairness" (i.e. the test of "fairness" from which price terms are exempt ${ }^{109}$ ), yet this should not distract from, or be taken to contradict, a key argument running through this article, i.e. that when thinking of an underlying ethic that favours rules setting a higher level of protection, "need" is a preferable theoretical label than "fairness". It just so happens in this case that following a need ethic would involve subjecting a broader range of charges to what is formally known as a "fairness" test: The point is that although the fairness test can itself be interpreted in either need oriented or self-interest/reliance oriented ways, ${ }^{110}$ if charges are subject to this test, there is at least the possibility of a need-oriented interpretation of the test and therefore a need-based review of the charges. Now, to the core point here: as to the exemption of charges from this (potentially need-oriented) fairness test.

The CRA provides that, if a term is "transparent and prominent", it cannot be assessed for fairness if "the assessment is of the appropriateness of the price payable under the contract by comparison with the goods, digital content or services supplied under it". "111 This derives from art 4 (2) of the Unfair Terms in Consumer Contracts Directive (UTCCD), ${ }^{112}$ included to leave a degree of scope for freedom of contract, ${ }^{113}$ and previously enacted in the UTCCR 1999, Regulation 6 (2). Article 4 (2) UTCCD refers to the "adequacy" of the price (as did the UTCCR), but "appropriateness" apparently conveys the same idea, and must anyway be interpreted to mean the same thing while the UK remains in the EU. The idea is that (assuming the requisite transparency and prominence, ${ }^{114}$ discussed further below), the test of fairness cannot be used to assess whether the price is too high, given what is received in return (not precluding other types of fairness assessment, e.g. as to time of payment, or the right to vary the price). As the UTCCD is a minimum harmonisation Directive, ${ }^{115}$ Member States may provide a higher level of consumer protection, so the UK could have applied the test of unfairness to the price, but chose not to. However it is not this basic choice that concerns us here: rather, as indicated already, the particularly broad interpretation of 'price.'

\footnotetext{
${ }^{106}$ Above notes 14,17 \& related text.

${ }^{107}$ Previously see UTCCR, reg. 5 (1).

${ }^{108}$ S. 71: refelceting the decisions of the Court of Justice of the EU in C-240/98, Océano Grupo Editorial SA v Roció Murciano Quintero [2000] and C-243/08, Pannon GSM Zrt v Erzsébet Sustikné Győrfi [2009].

${ }^{109}$ S. 62

${ }^{110}$ C. Willett, "General Clauses", above note 1.

${ }^{111}$ S. 64 (1) (b) \& 64 (2).

112 93/13/EEC.

${ }^{113}$ C. Willett, Fairness, above note 27, 245-254; terms specifying the main subject matter are also exempted by art 4(2)/s. 64 (1) (a)

${ }^{114}$ Replacing the "plain and intelligible language" condition (UTCCR, 6 (2)/UTCCD art 4 (2)).

${ }^{115}$ Art 8
} 
There is little doubt that the "price" includes the basic charges payable for the core goods, DC or services; and there is sometimes justification for such charges not to be reviewed for fairness, given that (so long as the market is competitive), they are subject to competitive discipline. ${ }^{116}$ But what about other charges, e.g. those not routinely payable but which are contingent on some later (usually inadvertent) consumer act or omission: e.g. charges when consumers accidentally exceed an airline baggage allowance, or an agreed overdraft limit? To understand the CRA's approach to which charges count as the price, it is necessary to review how 'price' was interpreted under the UTCCR regime preceding the CRA. The key case is Abbey National, which dealt with terms providing for large bank charges to be made, e.g., where consumers exceeded agreed overdraft facilities. ${ }^{117}$ Under the terms, exceeding the overdraft facilities was not defined as a default or breach, but as the consumer choosing to be provided with a service. Following this logic, the obligation to pay the charge was not defined as compensation for the bank's loss; but as a charge for the bank's service, i.e. the 'service' of allowing the payment to be made from the account.

The Court of Appeal (CA) held that the "price" only covered charges that the typical consumer would consider 'essential' to the bargain; this not including charges for an unauthorised overdraft, which consumers would not have planned to take when first entering the contract: not being the "price", the substantive fairness of these charges could be assessed under the test of unfairness. ${ }^{118}$ This was overruled by the SC, which refused to distinguish between essential and non-essential charges; holding that identifying the "price" was "a matter of objective interpretation by the court". ${ }^{119}$ The SC accepted that charges flowing from consumer default were not the "price", ${ }^{120}$ but found that the charges under consideration were not default charges. Rather the SC accepted the manner in which the terms themselves described the situation, i.e. that the charges were payable for services; concluding that such charges counted as the "price", notwithstanding that they were not routine contractual payments, but were contingent on later consumer acts or omissions. ${ }^{121}$

The CRA's unfair terms regime is based mainly on work by the Law Commissions. ${ }^{122}$ The general thrust of the Law Commissions' analysis was that where charges are provided in exchange for a service, then even if this is contingent on some later inadvertent act or omission, ${ }^{123}$ such charges should (following the SC approach in Abbey) be treated as the "price"; albeit that they should only be excluded from the fairness assessment where they are both "transparent" and "prominent". ${ }^{124}$ The CRA apparently follows this approach. It repeats the reference to "price", and simply adds the transparency and prominence

\footnotetext{
${ }^{116}$ C. Willett, "General Clauses", above note 1.

${ }^{117}$ OFT v Abbey National and others [2009] UKSC 6; S. Whittaker, "Unfair Contract Terms, Unfair Prices and Bank Charges" (2011) 74 M.L.R. 106 and C. Willett, "General Clauses", ibid.

${ }^{118}$ Abbey National plc and Others v OFT [2009] EWCA Civ 116.

${ }^{119}$ OFT $v$ Abbey National, note 117, Lord Mance, at [113].

${ }^{120}$ Ibid, Lord Mance, at [102].

${ }^{121}$ Ibid., e.g. Lord Walker, at [47]. See Case C-26/13 Árpád Kásler, Hajnalka Káslerné Rábai v OTP Jelzálogbank Zrt [2014] holding that a charge is not the price unless there is a service in exchange, but not being clear whether contingent charges for contingent services can be the price. See Parking Eye Ltd v Beavis above note 29: no service, so the charge was not the price.

${ }^{122}$ Law Commissions, Unfair Terms (2005), above note 9; and Law Commissions, Unfair Terms in Consumer Contracts: Advice to the Department for Business, Innovation and Skills (London, 2013).

${ }^{123}$ E.g. the airline and bank charges discussed above in the text.

${ }^{124}$ Law Commissions, Unfair Terms (2013), above note 122, 3.109.
} 
conditions. ${ }^{125}$ This suggests that the intention is that any charge is the "price", even where neither the charge, nor the "service" it pays for, is "essential" to the contract, e.g. where the charge is contingent on post-contractual acts or omissions. If the intention was for only essential charges to count as the price, this would surely have been indicated expressly.

This very broad approach to the price exclusion is another manifestation of the CRA being influenced by the self-interest/reliance ethic. It enables businesses to impose high nonessential charges (exempt from any substantive fairness review) so long as they (i) define these charges such that they are accepted by the court to be for a service, and (ii) present them transparently and prominently. This places high expectations of self-reliance on consumers. Pre-contractually, they must take advantage of the transparency and prominence of any harsh non-essential charges that could come into play, consider what risk these pose; and if the risk is unacceptable, either try to bargain for their removal, or find another business who does not impose such charges. If none of this is possible, consumers must then take care not to do anything to trigger the charge (e.g. inadvertently go overdrawn, accidentally exceed an airline baggage allowance etc.).

From a need-based perspective, consumers have limited ability to take any of these forms of self-reliant action. Certainly the "prominence" and "transparency" conditions are intended to facilitate greater informed choice by consumers: ${ }^{126}$ these requirements replacing the previous "plain and intelligible language" requirement. ${ }^{127}$ A "transparent" term is one that is in plain and intelligible language, and also "legible". To be "plain and intelligible" a term must enable the consumer to "evaluate, on the basis of clear, intelligible criteria, the economic consequences for him which derive from [the term]". ${ }^{28}$

However, the need-based viewpoint is that none of this will have much effect: Consumers are unlikely to read standard terms, so "prominent" and "transparent" standard terms, will do little to inform them. Even if "prominence" means that charges must be specially highlighted in some way (and as discussed below, this is not clear), consumers are assumed generally to focus on the essential charges, certainly at least on those that are routinely payable, rather than on contingent charges. If they do read about contingent charges, they may find it difficult to assess whether the events triggering these charges are likely to occur - possibly assuming they will not occur. ${ }^{129}$ Consumers are therefore unlikely to feel the need to bargain for lower charges (if they did, they are unlikely to have the bargaining power/skill to be successful), or to make comparisons between different businesses' charges - so the charges will often be subject to very limited competitive discipline. ${ }^{130}$

Consequently, from a need-based perspective, exempting non-essential, especially contingent, charges, from the test of unfairness, is likely to result in significant consumer detriment. High contingent charges are an increasingly common business model: e.g. bank charges, charges for exceeding an airline's baggage limit, or forgetting to re-fuel a hired

\footnotetext{
${ }^{125}$ S. 64 (2).

126 Law Commissions, Unfair Terms (2013), above note 122, 3.23.

${ }^{127}$ UTCCR, reg. 7 (1).

${ }^{128}$ Árpád Kásler, above note 121, para 75.

${ }^{129}$ C. Willett, "General Clauses", above note 1, 423, 426, 428.

${ }^{130}$ Above note 43 and related text.
} 
car. ${ }^{131}$ It is rare that consumers make a positive choice to take up the 'services' which these charges supposedly pay for. The charges usually arise by inadvertence, which, from a needbased perspective would be understood within a frame of consumer vulnerability, cognitive overload and (understandable) human error. ${ }^{132}$ In addition, the relatively vulnerable financial position of most consumers means they have limited ability to absorb the losses caused. Through this lens, the CRA sets a low level of consumer protection in relation to the price term issue. A more need-based approach might have provided that a charge is only the price, if the obligation to pay it is one of the essential terms; or at least that it is not the price where it is "contingent" on some later consumer act or omission. Such charges would then be subject to the unfairness test, potentially protecting consumers when charges are too high, e.g. where they significantly exceed any loss caused to the business, and are not necessary to protect some other legitimate business interest. ${ }^{133}$ This would be much more protective than charges simply being validated by the processes of the business, i.e. by transparent and prominent presentation.

What of our other key question: as to the relationship between the competing ethics and legal clarity/certainty? It is true that the test of unfairness involves a degree of uncertainty: e.g. in relation to the charges discussed here, there needs to be an assessment of the business' real loss, what legitimate reasons there are for charging more than this, and how much the charge needs to be to serve these purposes. ${ }^{134}$ So, being guided by the needbased ethic (and applying this test) does compromise certainty to a degree.

However, the CRA approach, guided by the self-interest/reliance ethic, generates at least as much (if not more) uncertainty as the need-oriented approach. Key here is the requirement that a charge escapes the unfairness test if it is "prominent", i.e. "brought to the consumer's attention in such a way that an average consumer would be aware of the term". ${ }^{135}$ Yet there is much scope for debate as to what this requires. Must charges be highlighted in some way? Must they be separated out from the other terms? If so, is it sufficient if they are set out prominently and separately in the formal contract, or must they be in other literature, such as advertising, or other communications between the parties? Do charges sometimes need to be explained verbally whether by phone, or face to face? Is greater prominence required for more unusual or onerous terms $?^{136}$ Do consumers

\footnotetext{
${ }^{131}$ See CMA, Retail Banking Market Investigation: Provisional Decision on Remedies (London 2016), on the $£ 1.2$ billion paid in 2014 on unauthorized overdraft charges alone (para 59); and on requiring banks to set a monthly maximum charge (including fees for unauthorized overdrafts) (57), but many caps already set by banks are as high as $£ 100$ per month (e.g. Halifax).

132 The CMA propose requiring banks to warn consumers of imminent unauthorized overdrafts, and allowing a subsequent "grace period" (CMA, Retail Banking, ibid, para 56).

133 See Parking Eye v Beavis, above note 29 on the "legitimate interest" element of the test; note 110 and related text, on interpreting the formal legal "fairness" standard by reference to the need ethic. See also C415/11 Mohamed Aziz v Caixa d'Estalvis de Catalunya, Tarragona i Manresa (Catalunyacaixa) [2013], where the CJEU said that core to fairness was whether a "consumer would have agreed to the term concerned in individual contract negotiations" (para 76). This suggests an even more need-oriented standard of fairness, one placing greater emphasis on consumer interests, than in Parking Eye. In Parking Eye, the focus on the legitimate interests of businesses was actually based on reliance on the opinion of the Advocate-General in Mohamed Aziz (e.g. para 106-7), rather than on the opinion of the CJEU itself (the CJEU did not refer at all to the legitimate interests of businesses).

${ }^{134}$ Parking Eye $v$ Beavis, ibid.

135 s. 67 (4).

${ }^{136}$ The Law Commissions recommended this (Unfair Terms (2013), above note 122, ch. 2, 4.46, but it is not provided for expressly in the CRA (s. 67 (4)).
} 
sometimes need to give separate assent to the charges? In short, the "prominence" concept undermines the clarity policy goal by making disputes less predictable.

The price term issue is another instance in which the ethic of self-interest/reliance has had the strongest influence, the result being very limited consumer protection, and at least as much, if not more uncertainty as would have been caused by a need-based approach.

\section{Beyond Freedom and Fairness}

The examples in this Part further confirm that the competing ethics framework provides a better explanation of consumer contract law than the "freedom versus fairness" framework. For example, it was argued above in Section II that "self-interest/reliance" is more determinate than "freedom". This is borne out by the discussion on price terms: The CRA approach favours business self-interest by allowing businesses to impose high charges, subject only to satisfying process based standards (presenting charges transparently and prominently). Consumers must exercise an extremely high degree of self-reliance to protect themselves from such charges. This can be referred to also in terms of freedom: the business has freedom in what is charged, and the consumer is, at least on paper, free to decide whether to agree to such charges. The difficulty is that "freedom" can also be understood to mean something similar to the need ethic. On this reading, the argument would be that, even if non-essential charges are transparent and prominent, consumers are not "free" in any meaningful sense to make use of this information: being unlikely to read them, and usually unable to estimate the risks they carry or bargain for their removal. So the only route to "real" freedom for consumers is for the law not to define such charges as price terms, thereby allowing the fairness test to determine what charges consumers would agree to if they were "really" free to bargain, it being imagined that consumers would choose terms that are not too substantively harsh. In short, "freedom" can be understood in different ways. ${ }^{137}$ By contrast, the language of self-interest/reliance much more clearly indicates that (as under the CRA regime) the preference is actually for process based standards: under these standards the business can impose harsh outcomes on consumers, unless consumers have exercised a very high degree of self-reliance.

\section{Conclusions and New Research Questions}

This article has looked afresh at consumer contract law theory, developing a "competing ethics" framework and arguing that this is an ideal way to depict alternative visions as to levels of consumer protection: being more effective in this regard than the "freedom versus fairness" framework. The CRA has then been used as a case study to show that a tension between the competing ethics runs through the heart of consumer law, and to advance understanding as to the relationship between these competing ethics, consumer protection and legal clarity/certainty.

The issue of certainty/clarity is especially under-researched. This article has sought to provide new insights: building on traditional contract law and behavioural science work; and making fresh connections between clarity/certainty and the ethical underpinnings of consumer law. However, there is more to do on certainty/clarity. Future research should consider what consumer law can learn from (and contribute to) philosophical work on the

\footnotetext{
${ }^{137}$ See above at note 46 and related text.
} 
effects of language on human relations, and work on clarity of language in other areas of law and regulation such as corporate social responsibility. ${ }^{138}$

As yet, there is no clear pattern of empirical evidence to support or undermine the arguments made in this article: it will be important to continue to monitor patterns of detriment and dispute resolution, and to consider how any improvements or problems can be linked to the arguments made here as to protection, clarity, certainty and the competing ethics. In developing areas, e.g. the digital and sharing economies, it will be important to recognise the role of competing ethics in influencing choices as to how to balance business and consumer interests. For example sharing platforms such as airbnb or Uber would normally be thought of as agents who simply bring suppliers (property owners or drivers) and consumers together, and who are therefore directly responsible for the quality of what is provided. Yet, if policy makers are guided by the need ethic, such platforms should arguably be allocated a degree of responsibility: to take into account their powerful economic position, their influence over consumer expectations via advertising and marketing, and the fact that the actual supplier may not be a regular business that is well placed to provide redress where a problem arises.

More generally, an important point to emphasise about the ethical underpinnings of legislative rules is that government policy documents upon which the CRA was based made no explicit reference to any particular ethical positions underpinning the policy thinking. The claim of this article rather is that certain ethics are implicit in the approaches taken. Similarly, if future developments do not come with explicit reference to ethical allegiances, we will need to continue to draw appropriate inferences from the substance of the rules chosen.

A further important question is as to how the ethical balance in consumer contract law is influenced by stakeholder input. Based on the CRA example, in the case of the need oriented rules, there does not appear to have been any major conflict between stakeholders: these rules being supported by consumer groups, but there being no pattern of strong business resistance. ${ }^{139}$ It does appear, however, that businesses had some influence where choices were made to follow the self-interest/reliance ethic: there being evidence of businesses lobbying against introduction of an outcome-based standard for any services, and against subjecting more charges to substantive control under the unfairness test. ${ }^{140}$ Nevertheless, we should be clear that the stakeholders did not in these instances refer explicitly to their allegiance to an ethic of self-interest/reliance. Rather inferences as to this allegiance must be drawn from the policy position taken.

A further crucial question is as to how the ethical balance of UK consumer law will be affected by BREXIT. A very significant proportion of UK consumer law derives from EU law. Some of this is in the CRA rules, e.g. the cure remedies in sales contracts, and the unfair terms regime; while EU derived rules (e.g. on information and cancellation rights, unfair

\footnotetext{
${ }^{138}$ E.g. on philosophy, Austin emphasized that "to say something is to do something" (J.L. Austin, How to Do Things with Words (Oxford 1975), 94); and on the benefits of clarity (for legislators, courts and stakeholders) in regulating for social corporate responsibility, O. Osuji, "Fluidity of Regulation-CSR Nexus: The Multinational Corporate Corruption Example" (2011) 103 Journal of Business Ethics 31-57, 35.

${ }^{139}$ BIS, Consumer Rights Bill: Statement on Policy Reform etc., above note 93.

${ }^{140}$ Ibid, 23-26; and Law Commissions, Unfair Terms (2013), above note 122, 19.
} 
practices, and producer liability) are contained in other provisions. ${ }^{141}$ Much of this EU derived law has been relatively need-oriented and protective. We saw this with the cure remedies discussed above here. In addition, for example, the cancellation rights in distance and off premises contracts were new protections for UK consumers; UTCCD required the UK to extend control of unfair terms beyond terms excluding or restricting business liabilities, to terms imposing onerous obligations and liabilities on consumers $;{ }^{142}$ the Unfair Commercial Practices Directive (UCPD) required control of a wider range of unfair commercial practices than previously in the UK: ${ }^{143}$ and the Product Liability Directive required the UK to move from fault based to strict producer liability for defective products. ${ }^{144}$ Indeed, the relatively protective nature of EU consumer law is further emphasised when we note that these rules apply to consumers in general and not only to consumers that are especially vulnerable. In fact the UCPD sets an even higher standard of protection for more vulnerable consumers. In determining whether a practice is unfair, a key question is whether the practice ".... is likely to materially distort the economic behaviour ... of the average consumer". ${ }^{145}$ However, it is also provided that practices "likely to materially distort the economic behaviour only of a clearly identifiable group of consumers who are particularly vulnerable to the practice or the underlying product because of their mental or physical infirmity, age or credulity in a way which the trader could reasonably be expected to foresee, shall be assessed from the perspective of the average member of that group". ${ }^{46}$

BREXIT negotiations could result in the UK signing a free trade agreement with the EU e.g. as a member of the European Economic Area, meaning that the UK would be required to continue to comply with the above Directives. ${ }^{147}$ Equally some new bespoke trade agreement might be reached which requires continued compliance with these Directives.

However, assuming the UK does not sign up to a trade agreement requiring compliance with these Directives, where might we stand? The European Union (Withdrawal) Bill provides that "EU-derived domestic legislation ... continues to have effect in domestic law on and after exit day". ${ }^{148}$ However, there remain enormous uncertainties as to what will happen to the level of consumer protection. First, the Bill also provides that after exit day, courts are not bound by Court of Justice of the EU (CJEU) interpretations of these EU derived rules and cannot refer issues to the CJEU; ${ }^{149}$ rather the UKSC would have the final word. Yet, the CJEU has often given interpretations of EU consumer law rules that are strongly protective

\footnotetext{
${ }^{141}$ See, e.g. Consumer Contracts etc Regulations, above note 2, implementing Directive 2011/83/EU, Consumer Protection from Unfair Trading Regulations (CPUTR) 2008 SI/1277 implementing Directive 2005/29/EC \& Consumer Protection Act 1987 implementing Directive 85/374/EEC.

${ }^{142}$ C. Willett, "The Directive on Unfair Terms in Consumer Contracts and its implementation in the United Kingdom” (1997) 5 (2) E.R.P.L. 223; but note also the tensions between more protective (need) and information based ("self-interest/reliance) values both in the UTCCD itself and in CJEU interpretation of it: G. Howells, C. Twigg-Flesner and T. Wilhelmsson, Rethinking EU Consumer Law (Abingdon 2018), ch. 4.

${ }^{143}$ M. Koutsias and C. Willett, "The Unfair Commercial Practices Directive in the UK" (2012) 5 Erasmus Law Review 237.

${ }^{144}$ G. Howells and M. Pilgerstorfer, "Product Liability", in C. Twigg-Flesner (ed), Cambridge Companion to European Private Law, (Cambridge, 2010), Ch. 19.

145 2005/29/EC, art 5 (2) (b)/CPUTR, reg. 3 (3) (b).

${ }^{146}$ Art. 5 (3)/CPUTR, reg. 2 (5).

${ }^{147}$ EEA Agreement, art 72 and Annex XIX

${ }^{148} \mathrm{https}$ ://publications.parliament.uk/pa/bills/cbill/2017-2019/0005/18005.pdf , s. 2 (1)

149 S. $6(1)$
} 
of consumers, and the UKSC has a track record of distinctly non-protective interpretations. ${ }^{150}$ Second, after exit day the UK will obviously not be obliged to introduce new EU rules that may provide important consumer protections, e.g. rules that may emerge from the current review of EU consumer law. ${ }^{151}$ Third, in relation to those EU rules currently in place, how many will the UK government actually chose to retain long term? Repealing significant tranches of consumer protection might be considered unacceptable and/or politically unwise. Nevertheless, a different view could be taken: a neo liberal, strongly pro-business government, with points to prove about "taking back control" by releasing the country from "EU red tape", might repeal important consumer protections deriving from EU law. Indeed, such bad news might be able to be "hidden", given the enormous menu of Brexit related issues that will be on the political agenda over the coming years. Fourth, the UK could enter a trade agreement with the US and/or other countries, the terms of which might insist on low levels of consumer protection-the idea being that higher levels would impede trade.

In short, the BREXIT process could result in UK consumer law taking a radical shift along the spectrum to a position where self-interest/reliance is the dominant ethic. This makes the analysis here all the more significant, in demonstrating what self-reliance/interest based rules look like, and therefore what UK consumer law might look (more) like post BREXIT.

Finally, the analysis here is primarily significant in relation to UK consumer law, but it is also a relevant case study for law reformers and scholars in other jurisdictions: in terms of ideological tensions in consumer law, how these tensions affect consumer protection and legal certainty and clarity, and what may be lost by forsaking the European family.

\footnotetext{
${ }^{150}$ On CJEU interpretation of the UTCCD, H. Micklitz and N. Reich "The Court and Sleeping Beauty: The Revival of the Unfair Contract Terms Directive (UCTD)" (2014) 51 (3) C.M.L.R. 771; on the UKSC, C. Willett, "General Clauses", above note 1.

${ }^{151}$ European Commission, Results of the Fitness Check of Consumer and Marketing Law and of the Evaluation of the Consumer Rights Directive (Brussels 2017).
} 